\title{
Denture-Related Hyperplasia: A Clinical Study of a Turkish Population Group
}

\author{
Emin Murat CANGER ${ }^{1}$ \\ Peruze CELENK ${ }^{1}$ \\ Saadettin KAYIPMAZ ${ }^{2}$
}

\begin{abstract}
${ }^{1}$ Department of Oral Diagnosis and Radiology, Dental School, Ondokuz Mayls University, Samsun, Turkey ${ }^{2}$ Department of Oral Diagnosis and Radiology, Dental School, Karadeniz Technical University, Trabzon, Turkey
\end{abstract}

\begin{abstract}
Inflammatory fibrous hyperplasia (epulis fissuratum) (IFH) and inflammatory papillary hyperplasia (IPH) are oral mucosal diseases caused by ill-fitting denture wearing. A study was carried out on a group of Turkish people consisted of 131 female and 39 male complete denture wearers $(n=170)$ distributed in two age groups $(30-60$ and 60-80 years old $)$. The analysis of data collected from patients showed that while the incidence of IFH was higher in women than in men, the incidence of IPH was similar. Most lesions were found in the 30-60 year-old group. The incidence of lesions increased as the denture wearing period increased. Soft tissue growth was the main complaint of the patients with IFH and IPH. In the maxilla, the incidence of IFH was higher than IPH. There was also a significant difference between the distribution of the lesion types in the jaws. There were a larger number of lesions in the maxilla compared to the mandible and most IFH lesions were located in the anterior region of the jaws.
\end{abstract}

Key Words: complete dentures, denture-induced lesions, inflammatory papillary hyperplasia, inflammatory fibrous hyperplasia.

\section{INTRODUCTION}

Denture-related oral mucosal lesions (DML) such as denture-induced fibrous hyperplasia (IFH- epulis fissuratum) and inflammatory papillary hyperplasia (IPH) are more prevalent in older subjects than in younger individuals because the oral mucosa becomes more defenseless to local irritants as individuals age (1).

IFH is caused by low-intensity chronic trauma usually from ill-fitting dentures or even parafunctional habits. Lesions typically appear as a single or multiple hyperplastic tissue folds or as folds of hyperplastic connective tissue, covered with stratified squamous ephitelium in the alveolar vestibule. In the bottom of the fissures, severe inflammation and ulceration may occur. The size of the lesion varies from a localized hyperplasia off less than $1 \mathrm{~cm}$ in size to massive lesions that involve most of the length of the vestibule. It has been reported to occur $5-10 \%$ of jaws fitted with dentures and is more prevalent in maxilla than mandible. It is generally uneventfully healed after the reduction of offending flanges or extraction with minor surgery (2-4).

IPH is asymptomatic reactive tissue growth. Although the exact pathogenesis is not well-known, ill-fitting dentures, poor oral hygiene resulting in a localized infection by candida, wearing dentures all day, sensitivity to denture base materials, smoking, age-related changes, and systemic conditions are widely accepted as etiological factors. In addition, irritation and trauma to the palatal salivary glands and inappropriate relief chambers in dentures have also been suggested as possible causes. It has been suggested that palatal glands are more prone to inflammation under the denture plate. IPH is seen often after excessive bony resorption. This is especially true in the "Combination Syndrome". By the resorption of the maxillary anterior region, the maxillary denture moves upwards anteriorly and downwards posteriorly. This situation produces a negative pressure posterior to the fulcrum line. Early lesions may involve only palatal valute; advanced cases cover most of the palate. The mucosa is erythematous, and has a pebbly or papillary surface. Treatment can be achieved by the

Correspondence: Dr. Emin Murat Canger, Ondokuz Mayıs University, Faculty of Dentistry Department of Oral Diagnosis and Radiology, Samsun, Turkey. Tel: +90-362-3121919/3012. Fax:+90-362-4576032. e-mail: emcanger@omu.edu.tr 
removal of the denture. The condition may also show improvement after topical or systemic antifungal therapy. In advanced cases, excision of the hyperplastic tissues before construction of a new denture is applicable (4-7).

There is much in the literature on denture-induced acute or chronic lesions, but, to our knowledge, there are no studies about these lesions in the population of Turkey in English language journals. The purpose of this study was to investigate oral mucosal hyperplasia from the aspects of gender, age, denture use duration, location and involvement of dentures.

\section{MATERIAL AND METHODS}

This study was carried out on 170 patients of both genders who were diagnosed as having IFH, IPH or both in a group of 485 complete denture wearers who presented with various prosthetic complaints between 2003 and 2006. As much as 131 out of 170 patients were female $(77.1 \%)$ and 39 were male $(22.9 \%)$. All patients were within the age interval of $30-80$. Female were between 32-80 years (mean age $=55.94 \pm 10.12$ ) and male were between 30-79 years (mean age $=59.43$ \pm 12.63 years). Two major age groups of patients were formed: $30-60$ and $60-80$ year olds.

All patients completed a questionnaire regarding gender, age, duration of denture wearing, duration of the lesions and complaints. The dentures had been constructed in various clinics such as dental schools, government hospitals or private clinics, and there was no information about their construction technicalities or about information given to the patients. Intraoral examinations of all subjects were performed by one of the authors. IPH and IFH were diagnosed and classified according Neville et al. (4). The localization, clinical characteristics, and other clinical findings of the lesions were recorded. Information regarding gender, age, denture wearing period, duration of the lesions, patient complaints, location of the lesions was also collected.

Panoramic radiographic examination was carried out and the external surfaces of the dentures were examined. Patients were recommended to remove of ill-fitting dentures, and relining the denture with tissue conditioner to allow for regression of the lesions. However, in approximately $90 \%$ of the patients, lesions required surgical excision. This procedure was carried out at the Department of Oral Surgery of our School. After the healing period, the patients were referred to the Department of Prosthodontics and new dentures were constructed.

Statistical analyses of the results were performed using SPSS software version 12.0 (SPSS Inc., Chicago, IL, USA). Descriptive statistics were expressed as case numbers (n) and percentages (\%). Categories were compared with a chi-squared test. Statistical significance was defined by $\mathrm{p}<0.05$.

\section{RESULTS}

The distribution of lesions between the genders is presented in Table 1.127 patients $(74.7 \%)$ had IFH, 17 patients $(10 \%)$ had IPH, and 26 patients $(15.3 \%)$ had concomitant presence of IFH+IPH. The IFH and IFH+IPH groups presented no significant difference between the genders; however, the IPH group showed a difference $(\mathrm{p}<0.05)$. The incidence of IPH was $6.9 \%$ in women, and $20.5 \%$ in men.

The distribution of lesions according to age groups is demonstrated in Table 2. While there were not any statistically significant differences within the age groups in IFH and IPH ( $p>0.05)$, in the IFH+IPH group, there were differences between the 30-60 year old group and the 61-80 year group $(\mathrm{p}<0.05)$.

The relationship between the lesions and denture wearing duration is presented in Table 3. Ten patients who did not remember their denture wearing period clearly were excluded from this analysis. $68.5 \%$ of the patients with IFH, $76.5 \%$ with IPH, and $76.9 \%$ with IFH+IPH had been wearing their dentures more than 10 years. When the denture period increased, the incidences of the lesions were also increased. There was no statistically significant difference between denture wearing duration and lesions $(\mathrm{p}>0.05)$.

The distribution of the patient complaints is presented in Table 4 . In the IFH group, $34.4 \%$ of the patients had fibrous tissue growth, $14.8 \%$ experienced pain, $25 \%$ were complaining disuse of their dentures, and in $25.8 \%$ of them, the major application cause was the need for renewal of dentures. In the IPH group 1\% of the patients had stopped using their dentures, and $94.1 \%$ of the patients were in need of denture renewal. In the IFH+IPH group, $44 \%$ of the patients expressed that their major complaint was fibrous tissue growth, $5 \%$ complained of pain and $36 \%$ said that the need to renew their dentures was the major problem.

There was a statistically significant difference 
in the distribution of the lesion types within the jaws $(\mathrm{p}<0.05)$. There were more lesions in the maxilla than in the mandible (102-60\%/68-40\%). Most IFH lesions were located in the anterior region of the jaws (101$79.5 \%$ ). The same result was observed for IFH lesions in the IFH+IPH group (20-76.9\%). The mesial and distal of canines were accepted as the anterior and posterior regions, respectively. (Table 5).

\section{DISCUSSION}

Removable dentures can injure the oral tis-

Table 1. Distribution of the lesions between the genders.

\begin{tabular}{|c|c|c|c|c|c|c|c|c|c|c|c|}
\hline & \multicolumn{3}{|c|}{ IFH } & \multicolumn{3}{|c|}{ IPH } & \multicolumn{3}{|c|}{$\mathrm{IFH}+\mathrm{IPH}$} & \multicolumn{2}{|c|}{ Total } \\
\hline & $\mathrm{n}$ & $\%$ & $\mathrm{p}$ & $\mathrm{n}$ & $\%$ & $\mathrm{p}$ & $\mathrm{n}$ & $\%$ & $\mathrm{p}$ & $\mathrm{n}$ & $\%$ \\
\hline Women & 102 & 77.9 & $*$ & 9 & 6.9 & \# & 20 & 15.3 & $*$ & 131 & 100 \\
\hline Men & 25 & 64.1 & $*$ & 8 & 20.5 & \# & 6 & 15.4 & $*$ & 39 & 100 \\
\hline Total (n) & 127 & & & 17 & & & 26 & & & 170 & \\
\hline
\end{tabular}

$\mathrm{IFH}=$ Induced fibrous hyperplasia; IPH $=$ inflammatory papillary hyperplasia. $*(p>0.05) . \#(p<0.05)$.

Table 2. Distribution of the lesions according to age group.

\begin{tabular}{lccccccccccc}
\hline & & & & & IFH & & & IFH + IPH & Total \\
\cline { 2 - 9 } & $\mathrm{n}$ & $\%$ & $\mathrm{p}$ & $\mathrm{n}$ & $\%$ & $\mathrm{p}$ & $\mathrm{n}$ & $\%$ & $\mathrm{p}$ & $\mathrm{n}$ & $\%$ \\
\hline $30-60$ yrs old & 82 & 64.6 & $*$ & 11 & 64.7 & $*$ & 11 & 42.3 & $\#$ & 104 & 100 \\
$61-80$ yrs old & 45 & 35.4 & $*$ & 6 & 35.3 & $*$ & 15 & 57.7 & $\#$ & 66 & 100 \\
Total(n) & 127 & 100 & & 17 & 100 & & 26 & 100 & & 170 \\
\hline
\end{tabular}

$\mathrm{IFH}=$ Induced fibrous hyperplasia; IPH $=$ inflammatory papillary hyperplasia. $*(p>0.05) . \#(\mathrm{p}<0.05)$.

Table 3. Relationship between the presence of lesions and denture wearing period.

\begin{tabular}{lccccccccc}
\hline & \multicolumn{3}{c}{ IFH } & & \multicolumn{2}{c}{ IPH } & & \multicolumn{2}{c}{ IFH + IPH } \\
\cline { 2 - 9 } & $\mathrm{n}$ & $\%$ & $\mathrm{p}$ & $\mathrm{n}$ & $\%$ & $\mathrm{p}$ & $\mathrm{n}$ & $\%$ & $\mathrm{p}$ \\
\hline $0-10 \mathrm{yrs}$ & 33 & 27.5 & $*$ & 2 & 13.3 & $*$ & 4 & 16.6 & $*$ \\
$>10$ yrs & 87 & 72.5 & $*$ & 14 & 86.7 & $*$ & 20 & 83.4 & $*$ \\
Total(n) & 120 & 100 & & 16 & 100 & & 24 & 100 \\
\hline
\end{tabular}

$\mathrm{IFH}=$ Induced fibrous hyperplasia; IPH = inflammatory papillary hyperplasia.* $(\mathrm{p}>0.05)$. 
sues, and there is an association between DML. DML constitute one of the reasons for dissatisfaction with removable dentures, and are more prevalent within the female population $(4,8)$.

Although MacEntee (9) found that the incidence of DML was higher in men than women, there are many studies indicating the high prevalence of DML among females. Coelho et al. (8) carried out a study on 305 patients, and reported that IFH was observed in 42 females and 14 males. In a survey on oral mucosal disorders in denture wearers, Dorey et al. (10) found that $6 \%$ of 156 lesions were IPH and $2 \%$ were IFH; $76 \%$ of all patients in the study were females. Nevalainen et al. (11) reported that from a total of 338 subjects, 18 had IPH and 7 had IFH. Among these patients, females represented $12 \mathrm{IPH}$ cases and 5 IFH cases. Similarly, in the study of Jainkittivong (12) involving 500 patients, 10 patients had IFH and 6 of them were female. Mikkonen et al. (6) reported that $17 \%$ of approximately 1,900 patients had hyperplasia and the prevalence of them was higher among the females. In the study of Espinoza et al. (13), women more frequently had DRL than men, and Firoozmand et al. (14)

IFH = Induced fibrous hyperplasia; IPH = inflammatory papillary hyperplasia.

Table 5. Localization of the lesions.

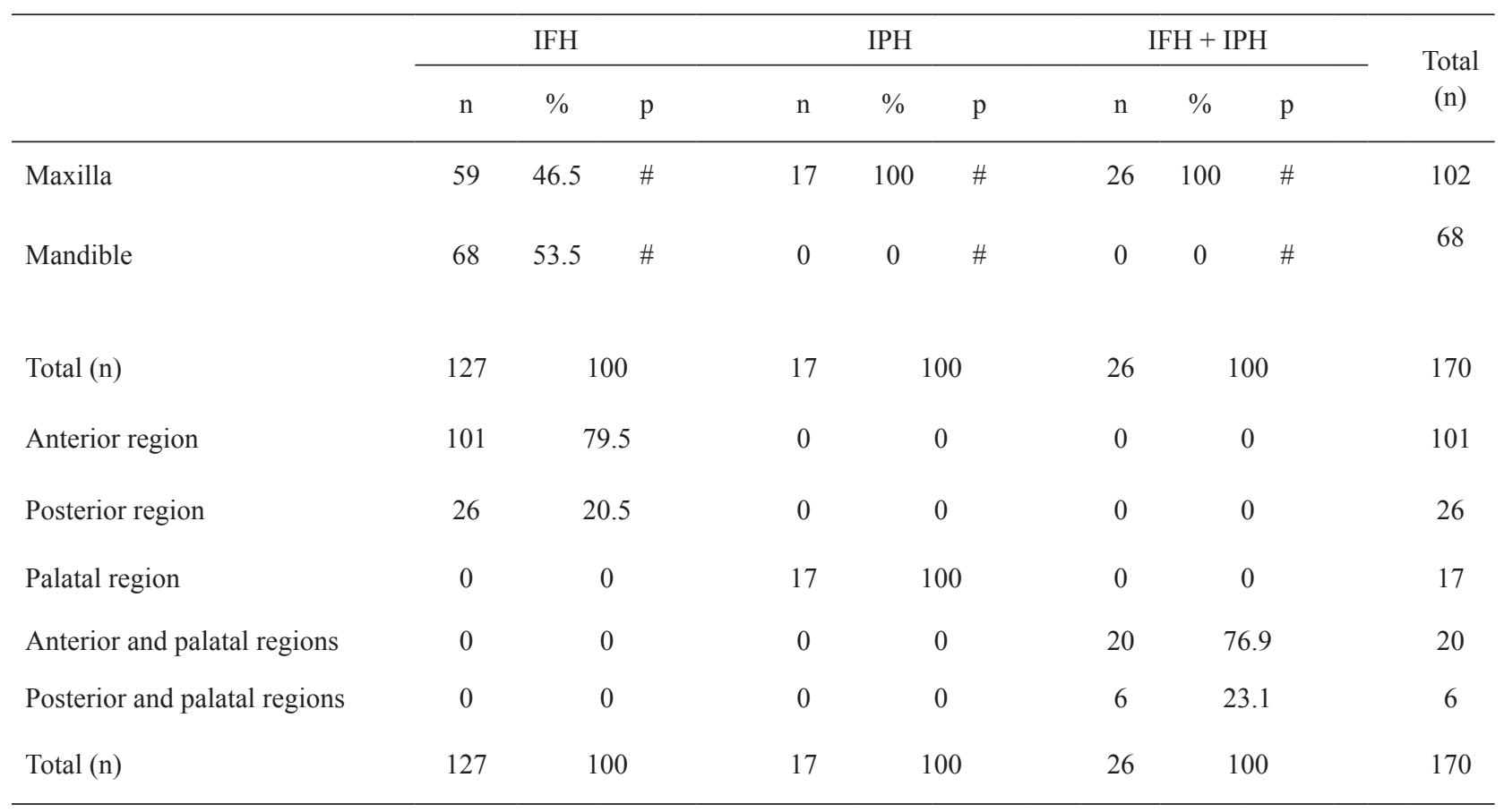

$\mathrm{IFH}=$ Induced fibrous hyperplasia; IPH $=$ inflammatory papillary hyperplasia. $\#(\mathrm{p}<0.005)$. 
reported in their study that $78 \%$ of IFH cases occurred in females.

The present results are in accordance with those of previous studies, as the 131 of IFH and IPH cases among 170 patients were seen in females. This high prevalence of IFH and IPH within the females can be attributed to the facts that females live longer than males, surveys show that elder women wear dentures as compared to men, and women have a tendency to seek dental treatment more often than males because of esthetic and cosmetic reasons $(4,8,10,11)$. Additionally, females tend to wear their dentures for longer periods than do males $(4,8,14)$. Postmenopausal changes and hormonal deficiencies also make the oral mucosa more susceptible to hyperplastic changes $(4,10,14)$. Results of our study also indicated that 96 of 132 women were post-menopausal (age 50 and older).

In a study of oral mucosal lesions among geriatric persons in Israel (15), $52 \%$ of denture wearers had ulcerative or proliferative lesions and $43 \%$ of them were complete denture wearers; $34 \%$ had removable partial dentures. This situation may be explained by the fact that the area of oral mucosa covered by a complete denture is greater than that covered by a partial denture.

IFH occurs at a higher rate in the maxilla $(3,8)$ than in the mandible. A previous study regarding denturerelated oral mucosal lesions in a Brazilian dental school (8) found that the majority of FIH cases occurred in the maxilla. Another study evaluating the oral status and prosthetic factors related to residual ridge resorption in elderly subjects (16), $2 \%$ of IFH and $3 \%$ of IPH were observed in the mandible. The corresponding figures for maxilla were $8 \%$ and $2 \%$ respectively. But there are some contradictory results, such as those in the De Baat et al. study (17), which was carried out on 397 patients, of whom 103 ( $26 \%$ of all cases) had IFH, and showed that $18 \%$ of cases were present in mandible and $8 \%$ in maxilla. Interestingly results of our study were in conjunction with the results of De Baat et al. (17) as the $46 \%$ of IFH was located in the maxilla but $53.5 \%$ in mandible.

A previous study assessing oral mucosal lesions and oral hygiene habits in home-living elderly (11) found that 5 of 8 IFH cases were in the mandible. Similarly, in the present study, the majority of IFH lesions was seen in the mandible (53.5\%) compared to the maxilla $(46.5 \%)$. This situation may be explained by the fact that the area of mucosa covered by a denture is greater in the maxilla than the mandible so the pressure being inserted to the underlying mucosa is higher in maxilla.

The anterior regions of the jaws are more often affected by IFH than are the posterior regions $(3,18)$. The results of our study on these lesions in the population of Turkey support this information, considering that $77.5 \%$ of IFH were in the anterior region.

Accepted as a denture-related lesion, IFH most often occurs in middle aged and older adults (4). Similarly, Dundar and Kal (19) carried out a research on 700 elderly denture wearers and concluded that patients older than 70 years presented more IFH lesions than younger individuals. It is interesting that in the present study a great proportion of the patients were in the 30-60 years group and in the fifth decade of life. They were also a little bit younger than the patients of other studies $(8,11,12)$. To explain this situation, it may be said that, in Turkey, people lose their teeth and become edentulous earlier than in many other countries.

In the present study, most patients with IPH were just in need of denture renewal and disuse of their dentures. Pain was present only in the concomitant cases of IFH and IPH. In our study pain can be attributed to IFH solely, since the IPH is usually asymptomatic (4).

In the current study, $69.8 \%$ of IFH group and and $76.5 \%$ of IPH group had been wearing ill-fitting dentures continuously during the whole day. The average denture wearing of that group was more than 10 years. As the patient's age increased, the length of denture use also increased. Older people are more reluctant to replace or restore their old dentures (8). Thus, with long-term use of traumatic dentures, denture-induced lesions, such as IFH and IPH, become more frequent (8).

A great period of time wearing dentures is accepted as a possible cause of IPH and IFH. Dundar and Kal (19) reported that the incidence of oral mucosal lesions (including IFH and IPH) was higher in individuals who had used their dentures for more than 20 years. A study on 146 complete denture users concluded that the incidence of IPH was associated with the time of use (20). Accordingly, we found that the incidence of both IFH and IPH was higher in individuals who had used their dentures for more than 10 years This was explained by the possible longer traumatic effect of a defective denture, and by the fact that defects might be more severe in old dentures than new ones. However, in addition to the wearing period, denture cleansing and the denture base material must be taken into account. 
It is well known that hyperplasia related to denture use originate from chronic irritation. Patients and their relatives express anxiety when reporting to dental clinics for examinations. To avoid denture induced hyperplasia, dentures must be examined more often after their construction and delivery, the patients must be informed about cleansing and disinfection measures, and warned not to wear them a whole day at a time.

\section{RESUMO}

A hiperplasia fibrosa inflamatória (epulis fissuratum) (HFI) e a hiperplasia papilar inflamatória (HPI) são doenças da mucosa causadas por próteses mal-ajustadas. Foi feito um estudo num grupo de pessoas, na Turquia, composto por 131 mulheres e 39 homens $(\mathrm{n}=170)$ usuários de próteses totais. O grupo foi subdividido em duas faixas etárias ( 30 a 60 e 60 a 80 anos). A análise dos dados coletados dos pacientes mostrou que a incidência de HFI foi mais alta entre as mulheres, ao passo que a incidência de HPI foi similar em ambos os sexos. A maioria das lesões foi encontrada no grupo indivíduos de 30 a 60 anos. A incidência das lesões aumentou com o tempo de uso da prótese. A queixa principal dos pacientes com HFI e HPI foi o aparecimento de tecidos moles. A incidência de HFI foi maior do que HPI, na maxila. Houve também diferença significativa de distribuição dos tipos de lesão nos maxilares. Houve maior número de lesões na maxila, em comparação com a mandíbula e a maioria das lesões HFI estava localizada na parte anterior dos maxilares.

\section{REFERENCES}

1. Lin HC, Corbert EF, Lo EC. Oral mucosal lesions in adult Chinese. J Dent Res 2001;80:1486-1490.

2. Carlsson GE. Clinical morbidity and sequale of treatment with complete dentures. J Prosthet Dent 1997;79:17-23.

3. Xie Q, Ainamo A, Tilvis R. Association of residual ridge resorption with systemic factors in home-living elderly subjects. Acta Odontol Scand 1997;55:299-305.

4. Neville BW, Damm DD, Allen CM, Bouquot JE. Oral \& maxillofacial pathology. 2nd ed. Philadelphia : Elsevier; 2004.

5. Infante-Cossio P, Martinez-de-Fuentes R, Torres-Carranza E, Gutierrez-Perez JL. Inflammatory papillary hyperplasia of the pal- ate: Treatment with carbon dioxide laser, followed by restoration with an implant-supported prothesis. Br J Oral Maxillofac Surg 2007;45:658-660.

6. Greenberg MS, Glick M. Burket's oral medicine. Diagnosis \& treatment. 10th ed. Ontario : BC Decker; 2003.

7. Kelly E. Changes caused by a mandibular removable partial denture opposing a maxillary complete denture. J Prosthet Dent 2003;90:213-219.

8. Coelho CMP, Sousa TCS, Dare AMZ. Denture-related oral mucosal lesions in a Brazilian school of dentistry. J Oral Rehabil 2004;31:135-139.

9. MacEntee MI, Glick N, Stolar E. Age, gender, dentures and oral mucosal disorders. Oral Dis 1998;4:32-36.

10. Dorey JL, Blasberg B, McEntee MI, Conklin RJ. Oral mucosal disorders in denture wearers. J Prosthet Dent 1985;53:210-213.

11. Nevalainen MJ, Narhi TO, Ainamo A. Oral mucosal lesions and oral hygiene habits in the home-living elderly. J Oral Rehabil 1997;24:332-337.

12. Jainkittivong A, Aneksuk V, Langlais RP. Oral mucosal conditions in elderly dental patients. Oral Dis 2002;8:218-213.

13. Espinoza I, Rojas R, Aranda W, Gamonal J. Prevalance of oral mucosal lesions in elderly people in Santiago, Chile. J Oral Pathol Med 2003;32:571-575.

14. Firoosmand LM, Almeide JD, Cabral LAG. Study of dentureinduced fibrous hyperplasia cases diagnosed from 1979-2001 Quintessence Int 2005;36:825-829.

15. Fleishman R, Peles DB, Pisanti S. Oral mucosal lesions among elderly in Israel. J Dent Res 1985;64:831-836.

16. Xie Q, Narhi TO, Juha MN, Wolf J, Ainamo A. Oral status and prosthetic factors related to residual ridge resorption in elderly subjects. Acta Odontol Scand 1997;55:306-313.

17. de Baat C, Van Aken AAM, Mulder J, Kalk W. Prosthetic condition and judgment of complete dentures. J Prosthet Dent 1997;78:472478.

18. Müller N, Pröschel P. Histological investigation of tissue reactions in the anterior and lateral alveolar ridges of mandible induced by complete dentures. Quintessence Int 1989;20:133-140.

19. Dundar N, Kal BI. Oral mucosal conditions and risk factors among elderly in a school of dentistry. Gerontology 2007;53:165-172.

20. Freitas JB, Gomez RS, De Abreu MHNG, Ferreira E Ferreira. E. Relationship between the use of full dentures and mucosal alterations among elderly Brazilians. J Oral Rehabil. 2008;35:370-374.

Accepted February 3, 2009 